\title{
New telescope agreed
}

\section{Washington}

THANks to the legislative legerdermain of West Virginia Senator Robert C. Byrd, the radiotelescope at Greenbank that collapsed unexpectedly last November (see Nature 336, 296; 1988) is to be replaced with a new and more sophisticated design.

Last week, Byrd succeeded in adding a $\$ 75$-million budget appropriation for a new telescope to a 1989 Dire Emergency Supplemental Bill that had to be rushed through Congress to provide $\$ 1,200$ million in emergency funding for the Veterans' Administration. Now that the bill has been signed into law, the National Science Foundation (NSF) receives an immediate bonus of $\$ 37.5$ million on top of its normal budget. The remaining $\$ 37.5$ million will be available when the new fiscal year begins on 1 October.

and provide high performance at $7-\mathrm{mm}$ wavelength, with some performance down to $2.5-\mathrm{mm}$ wavelength.

Details have not yet been decided and AUI may go for an unconventional design which would have the feeder, which sends the reflected signal from the main mirror to the electronic detectors, set off to one side. This would give an unblocked main aperture, and would also reduce the size of the sidelobes in the receiver's pattern of sensitivity, a particularly useful attribute in mapping large-scale hydrogen emission from the Galaxy.

A preliminary design will be completed this year, with engineering drawings ready next year. The telescope should be ready by 1995 . It will be especially good at looking for millisecond pulsars because, unlike the non-steerable telescope at

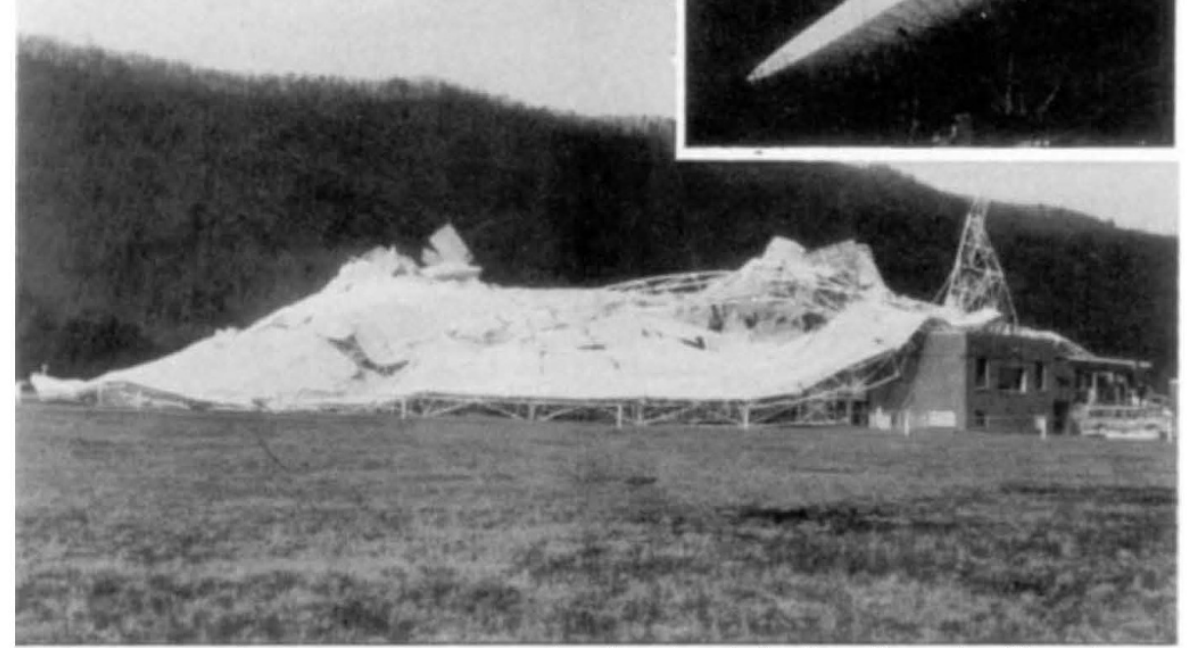

Greenbank: the 300-foot radiotelescope before (inset) and after its collapse last November

Replacing Greenbank was not the NSF's own top priority as it believed there were other, better ways to spend $\$ 75$ million than on an updated version of the 26-year-old, 300-foot telescope (see Nature 338, 448; 1989). But, as the only major scientific facility in his home state, Greenbank was at the top of Byrd's own list. Using his powerful position as chairman of the Senate Appropriations Committee, Byrd was able to please everyone by ensuring that the telescope would be rebuilt with funds that did not come out of the annual NSF budget.

Paul A. Vanden Bout, director of the National Radio Astronomy Observatory at Greenbank, says that a proposal for a new 100-metre telescope has already been submitted to NSF by Associated Universities Inc. (AUI), the consortium that runs the observatory. Unlike its predecessor, the new telescope will be fully steerable
Arecibo (Puerto Rico), it will be able see towards the Galactic Centre, where globular clusters containing millisecond pulsars are concentrated. The telescope's high performance at short wavelengths should also produce some firsts in the study of molecular clouds in distant galaxies, by allowing the detection of carbon-monoxide emission lines at unprecendentedly high redshifts.

In the future, the telescope could be linked to satellites that Japan and the Soviet Union plan to launch by 1995 , making it the terrestrial end of a spacebased very-long baseline array.

The budget success for Greenbank effectively ends alternative plans for keeping the facility alive by placing the eastern end of a proposed Laser Interferometry Gravity Wave Observatory (LIGO) at the site. Greenbank is not the most preferred location.

\section{$\mathrm{NIH}$ to end support for electronic network}

\section{Washington}

THE US National Institutes of Health (NIH) intends to pull the plug of the BIONET molecular biology electronic network at the end of the summer. In a message flashed across the network's electronic bulletin board last week, IntelliGenetics, the California biocomputing company that runs BIONET, advised its users at 925 laboratories to make "alternative" arrangements because NIH support will end on 30 September, forcing the company to shut down the network or restrict its services.

IntelliGenetics set up BIONET five years ago under a $\$ 5$ million "cooperative agreement" with NIH. Since then, the network has provided electronic mail services, access to DNA and amino-acid sequence and protein coordinate databases, and sequence-manipulation software to more than 2,000 users for a modest fee of $\$ 400$ per year.

But BIONET's money ran out earlier this year, and the NIH advisory committee that oversees the network declined to continue funding on the grounds that its research programme was weak. Unlike a contract, where a service is performed for a set fee, an NIH cooperative agreement requires grantees to conduct research programmes of the same calibre as those financed under competitive grants.

BIONET users have reacted strongly to the announcement. David Kristofferson, manager of BIONET at IntelliGenetics, has already received 25 electronic mail messages objecting to NIH's decision, and says his phone has been ringing constantly. An open letter soliciting comments on NIH's decision posted on the network by Dan Davison, a staff member from the GenBank DNA sequence database at Los Alamos National Laboratory, has collected nearly 50 responses from around the world.

But BIONET users may not be left totally out in the cold: Charles Coulter, head of the NIH office that administers BIONET, says he expects the "minimum capabilities" of BIONET to be transferred to the GenBank database. IntelliGenetics also runs GenBank, under an NIH contract, with support from the Department of Energy. NIH will decide next month whether to expand GenBank to include some of BIONET's services.

Kristofferson says beefing up GenBank may satisfy the needs of some users, but he fears that small laboratories may suffer. Now, anyone with a desktop computer and a modem can tap into BIONET's mainframe computer to sort sequences in GenBank without paying for a long-distance telephone call. Without BIONET, he says, "one way or another, people are going to pay more money".
Carol Ezzell 